ESTUDOS REEP

\title{
Cultura e resistência: a criação do popular e o popular como criação
}

Eliana P. G. de Moura

Dinora Tereza Zucchetti

Magali Mendes de Menezes

\section{Resumo}

Reflete sobre as inquietações do contexto contemporâneo, o esvaziamento das grandes narrativas e a fragilidade das utopias que ancoram as lutas e os movimentos sociais, para pensar o sentido da resistência. A análise é conduzida pela noção de cultura popular como campo que reflete as contradições do nosso tempo. Podemos ainda falar em cultura popular? Certamente, pois, diante da morte das utopias, mas também de sujeitos concretos e dos sonhos que são sua existência, é necessário pensar o popular como tradutor de um movimento criativo de resistência que ressignifica a vida.

Palavras-chave: cultura popular; resistência; vida; criação. 


\section{Abstract \\ Culture and resistance: the creation of the popular and the popular as creation}

This paper proposes a reflection about the contemporary context uneasiness, the undermining of the great narratives and the utopia fragility that maintain the social movements to think the meaning of the resistance. The analysis is conducted by the popular culture notion as place of nowadays contradictions. Is it still possible to consider a popular culture? Certainly, beyond the death of the utopias as well as concrete subjects and dreams that are their existence, it is necessary to think the popular culture as a translator of the creative resistance movement that ressignifies life.

Keywords: popular culture; resistance; life; creation.

Em breve, quando não houver fome, vai-se morrer de tédio ou de desespero. (Maffesoli, 2001, p. 21)

Por meio dessa reflexão, o autor da epígrafe coloca-nos diante de certo determinismo em que nem as lamentações nem as lutas sociais parecem ter mais sentido. Contudo, contestando essa posição de Maffesoli (2001) e de alguns pensadores, Canclini (2007, p. 29) afirma que estes parecem ter banalizado "as formas contemporâneas de desintegração, reduzindo-as a 'tribalismos'". Diante de posições aparentemente tão diversas, perguntamo-nos se é possível escapar a esta tragicidade. Não nos referimos à obviedade da morte, mas a certos estados de sobrevida que têm marcado a história da humanidade e, em tempos pós-modernos, nos fazem flagrar uma vida que se cansa rapidamente, perdendo forças, diluindo-se. Como resistir a isso, ou melhor, qual o sentido mesmo da resistência e ao quê ou a quem resistimos?

Resistir não implica somente posicionar-se diante de um mundo dividido entre norte e sul, oprimidos e opressores, esquerda e direita (conceitos estes, aliás, hoje profundamente fragilizados no campo político). Mesmo diante de tantas discussões ditas pós-modernas, que buscam desconstruir essas dualidades, deparamo-nos com o sentimento de que algo nos consome. Na medida em que coisas, ideias e instituições perdem sentido, sentimos a opressão que tenta nos impedir de desejar.

Por isso, perguntamos: Como é possível escapar à relação entre dominadores e dominados, quando percebemos, por exemplo, que grandes 
empresas transnacionais e governos de países-potências decidem, muitas vezes, o rumo de vários povos, culturas, vidas? Sabemos claramente que o poder se encarna nos meios de comunicação, conduzindo nossas vontades, modos de ser, sonhos e destinos políticos. Temos visto as "pequenas" lutas, aquelas que não são mais pensadas a partir de grandes revoluções - as chamadas revoluções moleculares, defendidas por alguns pensadores como sendo as únicas lutas possíveis -, capturadas ou mesmo diluídas no velho e grande "sistema".

Nesse sentido, Deleuze (1992, p. 218) afirma que

acreditar no mundo é o que mais nos falta; nós perdemos completamente o mundo, nos desapossaram dele. Acreditar no mundo significa principalmente suscitar acontecimentos, mesmo pequenos, que escapem ao controle [...]. É ao nível de cada tentativa que se avaliam a capacidade de resistência ou, ao contrário, a submissão a um controle.

Como então "suscitar acontecimentos", "escapar ao controle" quando o que nomeamos sistema torna-se concreto, atravessando a microfísica das relações através de uma perversa engrenagem capaz de capturar de forma sutil aqueles que o subvertem? Podemos citar aqui inúmeros exemplos de movimentos sociais, ideias e posturas que buscaram romper com essa lógica que se materializa no rosto da fome, da miséria e das duras injustiças sociais. Estas foram paulatinamente resumindo-se a um produto, uma boa ideia de marketing. Basta olhar o rosto de Che Guevara, como uma das imagens que mais circulam no mundo, estampado em camisetas vendidas em shoppings, usadas por jovens que nem ao menos têm consciência do que esse sujeito representou para a história da América Latina.

Do mesmo modo, podemos pensar as lutas ecológicas que denunciam uma razão instrumental moderna ancorada na necessidade de "controlar a natureza", colocando-a a serviço do homem, não importando as consequências que essa postura possa trazer ao planeta. Essa denúncia tornou-se hoje uma importante propaganda para as grandes empresas, que se utilizam da imagem de "politicamente corretas" em relação à sustentabilidade de seus produtos e seus possíveis impactos ambientais. Em outras palavras, a grandeza da crença de que o mundo pode ser diferente do que até então o fizemos parece estar na mesma direção da ideia de que nada pode ser mudado. A universalidade das utopias possui a mesma dimensão da universalidade do vazio. A absoluta liberdade torna-se bandeira, porque acreditamos na escravidão absoluta. É dessa forma que a modernidade representou o tempo das utopias e, simultaneamente, a desconfiança de que o utópico é possível.

É nesse sentido que Lyotard (2000) comenta o quanto é necessário "desconfiar" das metanarrativas (e de seus sistemas), ou seja, descrer desse grande projeto que sustenta e legitima a Modernidade. "[...] Considera-se 'pós-moderna' a incredulidade em relação aos metarrelatos." (Lyotard, 2000, p. 16). Desconfiar não é negar sua existência, mas colocar em cheque seu projeto. Lyotard questiona, então, em que lugar legitimaremos nossos discursos, se as grandes narrativas não mais se sustentam. 
Progresso, civilização, cultura, democracia, emancipação, humanidade e tantos outros conceitos traduziram a Modernidade como um projeto necessário e incondicional. No entanto, ao colocarmos uma lente de aumento nessas ditas universalidades, percebemos que fizeram a defesa de um modo de ser, excluindo tudo e todos que não se identificavam ou não se enquadravam nelas. O universal se sustentou desse modo, por meio de uma violência totalitária, imanente a sua compreensão.

Para onde, então, escoam os restos, essas sobras que não cabem na "universalidade"? Essa pergunta nos põe diante de contradições, pois reconhecer a existência de restos é negar o sentido mesmo da universalidade. Mas talvez se concentre aí justamente nosso desafio, ou seja, pensar rompendo com as contradições (que estão permeadas por compreensões duais). Pensar uma experiência que não pode ser reduzida a um sistema "significa buscar manter aberta qualquer síntese, conceitual ou material, que os poderes mais fortes tentem impor" (Negri, Cocco, 2005, p. 16). Os restos, dessa forma, carregariam em si uma força de resistência e de rompimento com a ordem que os nega? Ou a ideia de resto também tem seu lugar definido nessa universalidade?

A partir dessas questões iniciais, o que queremos aqui pensar emerge das inquietações presentes nesse contexto contemporâneo. Mais do que pensar se a pós-modernidade se contrapõe, complementa ou se apresenta como possibilidade de revisão crítica da insuficiência dos ideais modernos, ${ }^{1}$ queremos trazer a reflexão a respeito da(s) cultura(s) como um campo que expressa a densidade dessas problemáticas. As questões trazidas anteriormente, quando pensadas a partir da cultura, redimensionam-se. Assim, a temática central deste ensaio concentra-se na reflexão sobre a cultura enquanto expressão e identidade de um coletivo e, ao mesmo tempo, como fluidez, constante mudança. Onde se sustenta a sua possibilidade de resistência? Em sua capacidade de manter-se ou de transformar-se?

Maffesoli (2001, p. 27) comenta em relação a esse contexto contemporâneo: "[Quebram-se] os grilhões e os limites estabelecidos, e quaisquer que sejam seus domínios: político, ideológico, profissional, cultural ou cultual, as barreiras desmoronam. Nada pode represar seu fluxo." O problema é que, ao "quebrarem-se grilhões", quebram-se junto histórias, culturas, e, na fluidez desse "rio", veem-se arrastadas árvores, paisagens, vida. A imagem do rio nos faz recordar Heráclito quando reflete sobre a única coisa que realmente é permanente: a mudança (Souza, 1996) - aporia de difícil compreensão que nos convoca a penetrar nesse constante devir, contrário a uma racionalidade (ocidental) que percebe, na inconstância, na fluidez, na não linearidade, o caos.

De que maneira, então, o caos pode tornar-se revolucionário? Quando olhamos, por exemplo, as manifestações populares ocorridas na Tunísia, no Egito, na Líbia - a chamada "Primavera árabe" - nos entusiasmamos com a capacidade de um povo em revoltar-se, construir estratégias de organização e mobilização social, conduzindo verdadeiras massas às ruas em busca de democracia. Contudo, ficamos céticos em relação aos rumos

\footnotetext{
${ }^{1}$ Em relação a essas várias compreensões sobre os fenômenos contemporâneos, Bauman (cf. 2011, p. 112) faz uma síntese das diferentes expressões que traduzem esse tempo: Anthony Giddens cunhou o termo "modernidade tardia", Ulrich Beck nomeia "segunda modernidade", Georges Balandier surmodernité, e Bauman, por sua vez, refere-se à "modernidade líquida".
} 
dessas mobilizações e de que maneira efetivamente constroem uma sociedade mais justa e democrática. Duvidamos, inclusive, do sentido mesmo da democracia quando o Ocidente, enquanto representante de um modelo democrático, não conseguiu garantir necessariamente a justiça social.

Ao pensarmos em povos que estão ameaçados de desaparecer, em deslocamentos e reconfigurações culturais que são frutos de um processo violento de expulsão e não reconhecimento do outro, em camadas expressivas da população que vivem na marginalidade, em novos processos de colonização que vêm travestidos por uma necessidade de diálogo entre grupos humanos, mas que, na verdade, transformam a diversidade cultural em produto de mercado, vamos percebendo a necessidade e a urgência de refletir sobre a cultura como e da resistência. Com isso, queremos mostrar que o exercício da resistência, em muitos momentos, constitui as culturas, em um movimento constante de autoafirmação; mas quando falamos da cultura da resistência também queremos mostrar um modo demarcado de resistir que imprime, aos coletivos, regras, formatos e jeitos de se organizar e de fazer resistência.

\section{Cultura e civilização}

Para pensarmos a cultura enquanto resistência, faz-se fundamental entender os diferentes significados de cultura. O conceito de cultura traduz uma diversidade de compreensões, que, de alguma forma, acompanha a maneira como o ser humano percebe o mundo e a si mesmo. Edward B. Tylor foi o primeiro a utilizar o conceito de cultura desde uma perspectiva antropológica, abarcando nesta dimensão "conhecimento, crenças, arte, moral, leis, costumes e outros hábitos adquiridos pelo homem como membro da sociedade" (Tylor apud Parker, 2005, p. 80). Nessa perspectiva, todo homem, de alguma forma, possui cultura, pois ao viver em sociedade assimila valores, sendo capaz de reconstruir esses mesmos valores e, assim, produzir sentido. A cultura, desse modo, está profundamente ligada a uma aprendizagem, diferenciando-se de uma visão elitista presente no início da modernidade. Nesse momento, a cultura estava delegada às grandes civilizações e às altas classes.

Norbert Elias (1994) faz uma interessante reflexão sobre a relação entre cultura e civilização. O autor mostra que, na França, cultura (culture) era associada a civilização, possuindo um caráter mais universal, enquanto na Alemanha a palavra que melhor expressava esse sentido era Kultur, que trazia em si a defesa de um certo nacionalismo. Civilização representava, pois, um processo, um movimento que ultrapassava o limite de uma nação ou de um povo. Civilização, portanto, conduzia à ideia de uma racionalidade, de um modo de ser, em que ser civilizado é muito mais do que ser francês ou alemão, é uma condição humana que todos devem perseguir. Por outro lado, Kultur destaca os aspectos particulares de um povo, a consciência que ele tem de si mesmo, o que Elias chamará de autoimagem. 
Essas diferentes percepções devem ser compreendidas a partir da história desses países. Durante muito tempo, a França serviu de referência a outras regiões. Falar e escrever em francês era um hábito que a nobreza buscava preservar, e, desse modo, almejava-se alcançar um grau maior de "civilidade". Isso explica em parte porque a Alemanha do século 17 era extremamente pobre em relação à França e à Inglaterra. É nesse contexto político e cultural que a França se expande e coloniza mais terras antes que a Alemanha. Aos poucos, os alemães fortalecem sua Kultur, e pensadores como Kant e Goethe são fundamentais nesse processo. Todavia, esse movimento iniciado na burguesia, entre os intelectuais, concedendo inclusive o reconhecimento da universidade alemã como espaço de excelência no saber, não encontra eco nos setores políticos da sociedade alemã, ao contrário do que ocorria na França.

Com o passar do tempo, civilização e cultura se confundem, e o que inicialmente representava um aspecto social vai se transferindo para a visão de nação. Quando a Europa começa a impor sua cultura aos povos não europeus, inicia-se o processo civilizador. Civilização passa, então, a representar um estágio social que visa derrotar a barbárie. ${ }^{2}$

Elias (1994, p. 23) diz que o conceito de civilização, depois de vários desdobramentos,

expressa a consciência que o Ocidente tem de si mesmo [...]. Com esta palavra, a sociedade ocidental procura descrever o que lhe constitui o caráter especial e aquilo de que se orgulha: o nível de sua tecnologia, a natureza de suas maneiras, o desenvolvimento de sua cultura cientifica ou visão do mundo.

Assim, a Filosofia Idealista (representada por Kant e Hegel) destaca a importância da formação (Bildung) para que se pudesse pensar esse "novo" homem. Essa formação não englobava apenas a aquisição de conhecimentos, mas fazia-se necessário assimilar aspectos também presentes no campo estético e moral. Dessa forma, cria-se a ideia de um homem culto, ou seja, possuidor de alta cultura, profundamente distante da baixa cultura, ou seja, do que poderíamos chamar de cultura popular.

Embora não tenham desenvolvido uma reflexão sobre a cultura, Marx e Engels realizam uma crítica à ideologia burguesa, que, de alguma forma, traz reflexos para a concepção de cultura. Imbuídos por um ideal emancipatório, pensam a possibilidade de libertação do proletariado desde o rompimento com um elemento que é central na continuidade do sistema capitalista: sua ideologia e a forma como mascara um processo de exploração e consequente opressão. Enquanto para uma burguesia emancipação estava associada à aquisição de cultura (elitista e civilizatória), para a classe operária, emancipar-se era justamente romper com essa cultura, vista como hegemônica.

Nesse sentido, Guattari e Rolnik (1986, p. 20) compreendem a cultura como "um mercado geral de poder", no qual o embate das forças repercute não apenas "sobre os objetos culturais, ou sobre as possibilidades de
${ }^{2}$ Bárbaro, etimologicamente, designava na Grécia todo povo estrangeiro, não grego. Posteriormente, para os romanos, bárbaro significará "incivilizado". 
manipulá-los e criar algo, mas também poder de atribuir a si os objetos culturais como signo distintivo na relação social com os outros".

Esse aspecto será fundamental para entendermos mais adiante o surgimento dos Estudos Culturais, que inicialmente foi influenciado pelo pensamento marxista. É desse modo que os Estudos Culturais representaram o "esforço para retirar o estudo da cultura do domínio pouco igualitário e democrático das formas de julgamento e avaliação que, plantadas no terreno da 'alta' cultura, lançam um olhar de condescendência para a não cultura das massas" (Johnson, 2004, p. 21).

Johnson defende que a cultura deve ser compreendida como processos culturais intimamente ligados a relações sociais, expressando questões de classe, gênero, etnia e raça, idade, entre outras. Essas relações não representam um universo em equilíbrio, mas traduzem relações de poder, entendidas aqui como relações de força entre esses diferentes elementos. Os processos culturais tornam-se locais (e movimentos) por onde as lutas sociais se configuram e reconfiguram. Ao mesmo tempo em que esta análise traz a influência de uma percepção marxiana da cultura, compreendida a partir de certa determinação do econômico e social sobre o cultural, Johnson avança no sentido de perceber nesses processos elementos que possibilitam uma recriação e uma consequente fuga desses universos.

É nessa perspectiva que Escosteguy (2004, p. 139) comenta que Hoggart, um dos principais representantes dos Estudos Culturais, interessa-se profundamente pelos estudos da cultura popular, por perceber que no "âmbito da cultura popular não existe apenas submissão, mas também resistência". Mas o que significa popular? Poderíamos perceber o popular como resistência ao suposto fatalismo anunciado por Maffesoli na epígrafe inicial?

\section{A dimensão popular da cultura: resistências e alternativas}

Em outro momento, colocávamos a pergunta sobre por que resistir. Partimos da constatação de que desde o nascimento lutamos pela vida. Ou seja, ao nascer, enfrentamos a tarefa paradoxal de estarmos sós e, ao mesmo tempo, profundamente dependentes do outro, buscando enfrentar a fome, a dor, a falta de afeto, a luz, o corpo que dói, o outro que não nos escuta quando choramos. Assim, resistir nesse momento é lutar com todas as forças pela vida, pela possibilidade de respirar, de sobreviver. É justamente na resistência à possibilidade de não sobreviver que nos constituímos no mundo. Como lembra Feitosa (2007, p. 29), "todo ato de resistência é uma resistência à morte". Logo, a possibilidade de não sobrevivermos ao nascer é algo dado, e superá-la exige força que emerge do atrito do corpo com o mundo, do prazer de expandir-se no contato com o outro e consigo mesmo. Ao resistirmos, afirmamo-nos como sujeitos, não apenas quando nos colocamos contra o cumprimento de um projeto que se atualiza, mas também quando nos atiramos ao inesperado de todo e qualquer modo de existir. 
Resistir é, pois, criação, é inventar o próximo instante, na certeza e na angústia de que nada está pronto. Deixar de criar é deixar de resistir! É assim que resistir não é apenas "resistir a alguma coisa", como sugerem os dicionários.

Quero sugerir agora, desde Nietzsche e Deleuze, um outro significado para a palavra resistir, que não seja mais um resistir contra algo, mas um re-insistir. Resistência como uma forma especial de enfrentar o poder, de dizer não e sim, de agir conforme a liberdade, de lidar com a morte e com os muros da política. (Feitosa, 2007, p. 25).

Resistir é insistir, persistir mesmo que a morte seja certa, que o espaço pareça pequeno para nos movimentarmos, mesmo que os contratos já estejam feitos, que o tempo nos envelheça. Nesse sentido, Santos (2009), ao pensar a ideia de resistência, afirma que resistir é, de alguma forma, resistir ao velho como uma negação ao já estabelecido. Contudo, para o autor, é necessário avançar nessa posição e não apenas resistir, mas criar alternativas que seriam a afirmação do novo - ou seja, resistência sem alternativa não transforma a realidade.

Mas de que maneira, então, a cultura pode tornar-se resistência e, ao mesmo tempo, alternativa? Quando assume sua capacidade criativa, quando se reinventa, insistindo na possibilidade de refazer-se, de tornar-se grito coletivo pela vida. É assim que compreendemos a cultura popular: como uma dimensão da criação coletiva da resistência que potencializa alternativas. Como diz Santos (2001), precisamos também de alternativas às alternativas. É possível perceber isso em muitas experiências populares, que, de alguma forma, nos fazem repensar o campo político, econômico, social, afetivo e estético.

Nessa perspectiva, o popular como dimensão importante de criação é resgatado pelo filósofo argentino Rodolfo Kusch (1978), que faz importante reflexão sobre o sentido do popular e seu significado para o pensamento latino-americano. Todo e qualquer pensar emerge da relação do homem com seu espaço, isto é, desde uma geografia compreendida aqui não apenas como território, mas como solo, terra, por onde caminhamos e sentimos o mundo. Geralmente, quando pensamos o popular o relacionamos com uma ideia de povo que carrega em si a ambiguidade de representar a totalidade daqueles que pertencem a uma nação e, simultaneamente, ser uma parte dessa totalidade. Nesse sentido, o povo está marcado por questões de ordem econômica, vividas por uma parcela da população que se vê caracterizada por uma realidade feita de precariedades. Kusch comenta, todavia, que esta é apenas uma dimensão do econômico e que não podemos reduzir o humano a essa dimensão. Assim, a própria ideia de econômico se reconfigura, não reduzindo o humano a um "problema de coisas" (Kusch, 1978, p. 57). O povo, que produz a chamada cultura popular, representa, nas leituras hegemônicas, uma parcela da população que não tem suas necessidades básicas satisfeitas tout court.

No entanto, segundo Kusch (1978), não podemos analisar o problema econômico sem antes pensarmos um novo modo de ver os 
problemas da vida, ou seja, de pensarmos o(s) sentido(s) da vida. Para isso, faz-se necessário outro modo de conhecer outra epistemologia que não "desperdice as experiências", como destaca Santos (2000). Do campo popular surgem significativas experiências que produzem novos saberes, que, no entanto, não são valorizados como relevantes, por exemplo, pela própria universidade. Kusch (1978) se pergunta sobre como é possível instrumentalizar uma análise a partir do popular. Para o filosofo, a relação entre pesquisador e pesquisa sempre nos coloca no campo da interculturalidade, ou seja, pensar as experiências populares exige certo deslocamento, pois temos imensa precariedade de "categorias para compreender a dimensão de alteridade do marginalizado" (Kusch, 1978, p. 59). O popular desafia uma compreensão do conhecimento que é determinada por sua objetividade, isto é, por sua capacidade de delimitação do objeto.

Contudo, há no campo popular (mas não só; poderíamos transpor essa problemática a toda pesquisa social) algo que escapa a qualquer possibilidade de determinação que estaria na dimensão do simbólico. Assim, a cultura é atravessada por uma impossibilidade de determinação em que o símbolo não representaria apenas algo, substituindo-o, ficando em seu lugar. A dimensão simbólica presente na cultura popular, segundo Kusch, carregaria em si a força da experiência popular.

Há nesse movimento uma tradução (como todo diálogo exige), mas que necessita uma constante (re)tradução, pois a cultura é abertura ao incomensurável, impensável, em que a própria palavra é sempre mais do que ela diz; ou seja, o simbólico não substitui, não (re)apresenta o que deixaria de se apresentar, mas comporta em si a necessidade de uma constante apresentação. Talvez pudéssemos pensar que aí se encontra sua capacidade de resistência, ou seja, reinventar a palavra, ou outras formas de expressão, na densidade de todo silêncio; (re)aparecer no vazio de toda ausência.

Visando trazer mais elementos para pensarmos o popular, lembramos que Freire e Nogueira (2007) afirmam que a dimensão popular da cultura está nos saberes, no conhecer e na luta pela vida. "Buscar soluções populares é, ao mesmo tempo, modificar as relações com este mundo; nessas mudanças é que se elabora uma visão de transformação", afirma Brandão, dialogando com Freire e Nogueira (2007, p. 10).

A partir disso, entendemos que é pouco possível compreender a dimensão popular da cultura e seus sentidos de resistência sem, necessariamente, recuperar os escritos de Paulo Freire. Neles, quer por uma análise epistemológica do conhecimento, quer pela via da denúncia que grita diante das injustiças do mundo, vamos encontrar a cultura como categoria central.

Em ambas as perspectivas, as inúmeras possibilidades de conceituar cultura estão, para Freire, coladas na experiência (de vida e trabalho) de homens e mulheres. Por isso, defende uma visão pedagógica da cultura, em oposição a uma ideologia fatalista e imobilizante que, segundo ele, anima o discurso neoliberal. "Com ares de pós-modernidade, insiste 
[a ideologia fatalista] em convencer-nos de que nada podemos contra a realidade social que, de histórica e cultural, passa a ser ou a virar 'quase natural'" (Freire, 1997, p. 21).

Cultura é, também, um entre os temas geradores fundamentais à alfabetização/educação (de adultos), na medida em que permite resgatar, por meio dos círculos de cultura, a experiência de grupos - tendo o diálogo como a matriz de que aprender é aprender a "dizer a sua palavra". Assim, a educação centrada no aluno e sua experiência individual (coletiva) é prática pedagógica de ensinar e aprender, constituída na horizontalidade e na partilha dos saberes. Da sua dimensão coletiva, é possível destacar a emergência da pesquisa/ação social presente nas pesquisas de tipo participante com destaque para seu caráter emancipatório.

Merece destaque, nessa discussão sobre a cultura popular, a importância que assume, para Freire, o uso da palavra. Não de qualquer palavra, mas do "dizer a sua palavra", expressão que significa para o autor um ato de resistência capaz de instaurar um processo de reconhecimento da cultura (popular) pelo outro, o que, por sua vez, possibilita vivenciar a educação como prática de liberdade, ${ }^{3}$ porque esta é, em última instância, cultura popular. É interessante percebermos que, enquanto para Kusch (1978) a palavra é insuficiência, destacando, desse modo, uma dimensão anterior à palavra que carregaria em si sua força, para Freire é a própria força, empoderamento desse sujeito que, no uso da palavra, se escuta e é escutado.

Outra grande contribuição de Freire nasce no entremeio da experiência de grupos, da pessoalidade do educando, da condição popular da cultura, qual seja, o reconhecimento de que há outros espaços para o aprender, para além da instituição escolar. A emergência do reconhecimento desses outros espaços/tempos de educação fortalece a cultura popular como resistência ao modelo hegemônico escolar. ${ }^{4}$

É dentre o viver/aprender/resistir cotidianos, das práticas de educação para além da instituição escolar, que os movimentos sociais emergem e se impõem como importante espaço de luta e resistência, fomentando, especialmente, o reconhecimento de uma dada cultura. Nesse sentido, os movimentos sociais são, antes de tudo, movimentos de cultura (popular), o que lhes atribui, obviamente, caráter político.

Com amparo na concepção ampliada de educação e na dimensão cultural que advém das lutas oriundas das comunidades e dos movimentos sociais, ousamos afirmar que a dimensão popular da cultura, como resistência, nos permite pensar a emancipação de sujeitos que historicamente têm sido colocados à margem de processos de decisão política e de acesso aos bens imateriais e materiais. Assim, resistência e emancipação possuem uma complexa relação que implica uma análise do próprio projeto da modernidade. Sem que esse ensaio se ocupe dessa análise, aproximamo-nos de Santos (2000), em especial por meio da obra Pela mão de Alice: o social e o político na pós-modernidade, para reiterar a dimensão política da emancipação concebida como um conjunto de lutas processuais.

\footnotetext{
${ }^{3}$ Osowski (2008, p. 108) afirma que: "a produção de uma cultura freireana [...] matizou política e pedagogicamente o fazer docente e discente, posicionando educadores e educandos como sujeitos aprendentes, dando voz a quem não era escutado e criando condições para que os grupos culturais e movimentos sociais interferissem não só nas políticas educacionais, mas no próprio cotidiano da escola".

${ }^{4}$ Segundo Streck (2008, p. 541), a obra Pedagogia do oprimido "teve o mérito, entre tantos outros, de refazer a geografia das práticas educativas, colocando a escola como um dos espaços possíveis da educação. Este deslocamento foi importante para que décadas depois se assumisse a pluralidade de contextos educativos, ao mesmo tempo em que se passou a repensar o papel clássico da escola como instituição formadora da modernidade. Se na sociedade medieval não havia possibilidade de salvação fora da Igreja, na modernidade essa possibilidade começa a ser concentrada na escola. O dentro e o fora da escola passaram a ser vistos como o dentro e o fora da própria sociedade".
} 
Essas relações também estão presentes no pensamento de Freire (2000, p. 40), quando ele reflete sobre o conceito de resistência, ao afirmar que esta "tem a ver com a possibilidade de mudar o mundo, compreendê-lo dinâmico, recusando o discurso de que a mudança irá acontecer espontaneamente, ou seja, de que virá porque está dito que virá".

A partir desses autores, pensamos que a dimensão popular da cultura é capaz de produzir articulação, mobilização, movimento. Nesse sentido, a capacidade desse mesmo poder (da cultura popular) está em não sucumbir aos apelos midiáticos pela homogeneização da cultura, bem como aos processos da globalização que tendem a suprimir a riqueza das experiências locais das comunidades. Portanto, resistir significa, em última instância, gritar coletivamente por diferentes alternativas de vida.

\section{Considerações finais}

Mas por mais terrível que seja esta linha, é uma linha de vida que não se mede mais por relações de forças e que transporta o homem para além do terror. Pois no local da fissura, a linha forma uma fivela, "centro do ciclone", lá onde é possível viver, ou, mesmo, onde está, por excelência, a Vida.

(Deleuze, 2005, p. 130)

Este texto iniciou com uma epígrafe de M. Mafessoli, que constatava nosso destino trágico. Ao finalizarmos nossa escrita, percebemos que nossa reflexão sobre a dimensão da resistência presente na cultura popular direcionou-se na busca e opção pela vida. Por isso, nossas considerações finais iniciam com um pensador também contemporâneo que nos permite, de alguma forma, ter esperança. Trazemos a esperança aqui não para pensarmos uma condição de espera em que, passivos diante do que talvez nunca venha a acontecer, continuamos na imobilidade esperançosa do amanhã. Apostamos em um instante que se faz esperança, porque rompe com uma temporalidade linear, fazendo da resistência ao impossível, ao que se coloca como (u)tópico, a possibilidade mesma da vida.

Segundo Deleuze, a vida não está antes nem depois de todo processo de resistência, como se tivéssemos que recuperar algo perdido ou conquistar algo que ainda está por vir. A vida está justamente na própria resistência. É esse movimento que configura nossas forças, nossa vontade de potência. Perguntar se "resistir é possível" é, portanto, o mesmo que perguntar se viver é possível. Viver, então, é possível? Como diz o poeta Fernando Pessoa, "navegar é preciso, viver não é preciso". Não existe precisão no ato de viver e de resistir que poderia conceder à vida sua afirmação. Não se faz ciência da resistência; podemos calcular estratégias, planejar revoluções, traçar metas para cada passo que damos. 
Contudo, viver e resistir são sempre um constante reinventar, tarefa difícil para aqueles que esqueceram que na vida que resiste existe a arte de estar sendo. Ou seja, nossa condição de estar, nossa relação intrínseca com a terra na qual pisamos, vai penetrando nosso modo de ser, um ser não fixado numa estrutura perene (como pensavam os gregos ao definirem uma ideia de essência), mas atravessado pelo desafio de continuar sendo, numa linha muito ínfima e frágil que separa viver e não viver.

Por isso, quando falamos em cultura popular resgatamos a densidade dessa problemática. A cultura enquanto popular é, ao mesmo tempo, marcada pela trajetória de coletivos que insistem em viver, mas que, no processo mesmo da resistência, se (re)descobrem como algo diferente do que são.

Entretanto, não podemos desconsiderar, como recordam Guattari e Rolnik (1986, p. 23), que "não existe [...] cultura popular e cultura erudita". Em uma análise que radicaliza esses debates e discussões, afirmam que existe uma única cultura: a do capital. Segundo eles, "há uma cultura [do capital] que permeia todos os campos de expressão semiótica. [...] Há processos de singularização em práticas determinadas, e há procedimentos de reapropriação, de recuperação, operados por diferentes sistemas" do capital. Ou seja, Guattari e Rolnik alertam a respeito da possível armadilha que pode significar a defesa de uma cultura popular que, de alguma forma, sempre se percebe como a "cultura do pobre". Nossa maior resistência está em pensar o popular não mais como um adjunto da pobreza, mas como uma fresta que, desde a experiência da pobreza (que é inegável), nos permite criar.

Como, então, "ultrapassar a linha" da vida (até mesmo na experiência da pobreza) presente na epígrafe acima? - esta pergunta nos acompanha desde o início do texto. O próprio movimento de responder a essa questão flagra uma necessidade de resistir à impossibilidade de uma resposta. Resistir é, pois, responder, mas é também inventar novas questões, problematizar nosso tempo, não nos contentando com as perguntas já formuladas e suas respostas já dadas, com os destinos previstos, que nos deixam sem possibilidade de resposta e de esperança.

Resistir desde a experiência da pobreza é mais que resistir à pobreza, é suspeitar de suas leituras, da forma como a pobreza vai deixando marcas naqueles que a vivem. É assim que os conceitos e nosso instrumental teórico não "iluminam" a realidade que queremos pensar e parecem sempre insuficientes para compreender essas realidades. Todo e qualquer conceito deve ser problematizado a partir da realidade que queremos pensar. Temos que fazer esse constante movimento de sempre (re)alimentar nosso modo de olhar, refazendo-o, desconstruindo-o. Nossa percepção sobre o que seja resistir deve acompanhar o próprio movimento da resistência, ou seja, é o olhar que resiste a conceitos prontos ou estabelecidos, do mesmo modo que a cultura e sua adjetivação enquanto popular.

O popular pode, portanto, ser pensado como uma construção conceitual que define e emerge do sofrimento da vida, de uma resistência que se faz teimosia; popular como marca do povo; antítese necessária para 
que esses sujeitos possam dizer (a si mesmos) que existem. No entanto, nosso desafio encontra-se em não mais afirmar a construção do popular, conceito capaz de aderir-se facilmente a essa realidade, ratificando dicotomias, mas em pensar o popular - que se faz criação, reinventando-se a cada instante - como "devir popular", isto é, como força imanente à vida que resiste incessantemente, porque recusa submeter-se a todas as formas de morte.

\section{Referências bibliográficas}

BAUMAN, Zygmunt. Bauman sobre Bauman: diálogos com Keith Tester. Rio de Janeiro: Zahar, 2011.

CANCLINI, Néstor García. Diferentes, desiguais e desconectados. 2. ed. Rio de Janeiro: Editora UFRJ, 2007.

DELEUZE, Gilles. Conversações. São Paulo: Ed. 34, 1992.

. Foucault. São Paulo: Brasiliense, 2005.

ELIAS, Norbert. O processo civilizador: uma história dos costumes. Rio de Janeiro: Zahar, 1994, v. 1,

ESCOSTEGUY, Ana Carolina. Estudos culturais, uma introdução. In: SILVA, Tomaz Tadeu da (Org.). O que é, afinal, estudos culturais? 3. ed. Belo Horizonte: Autêntica, 2004.

FEITOSA, Charles. Revolução, revolta e resistência: a sabedoria dos surfistas. In: LINS, Daniel (Org.). Nietzsche, Deleuze: arte, resistência. Rio de Janeiro: Forense Universitária, 2007.

FREIRE, Paulo. Pedagogia da indignação: cartas pedagógicas e outros escritos. São Paulo: Unesp, 2000.

Pedagogia da autonomia. São Paulo: Paz e Terra, 1997.

FREIRE, Paulo; NOGUEIRA, Adriano. Que fazer: teoria e prática em educação popular. Petrópolis: Vozes, 2007.

GUATTARI, F.; ROLNIK, S. Micropolítica: cartografias do desejo. Petrópolis: Vozes, 1986.

JOHNSON, Richard. O que é, afinal, estudos culturais? In: SILVA, Tomaz Tadeu da (Org.). O que é, afinal, estudos culturais? 3. ed. Belo Horizonte: Autêntica, 2004. 
KUSCH, Rodolfo. Esbozo de una antropologia filosófica americana. Buenos Aires: Ediciones Castañeda, 1978.

LYOTARD, Jean-François. A condição pós-moderna. 6. ed. Rio de Janeiro: José Olympio, 2000.

NEGRI, Antonio; COCCO, Giuseppe. Glob( $A L)$ : biopoder e luta em uma América Latina globalizada. Rio de Janeiro: Record, 2005.

MAFFESOLI, Michel. Sobre o nomadismo: vagabundagens pós-modernas. Rio de Janeiro: Record, 2001.

OSOWSKI, Cecília. Cultura. In: STRECK, Danilo; REDIN, Euclides;

ZITKOSKI, Jaime José (Org.). Dicionário Paulo Freire. São Paulo, 2008.

PARKER, Cristián. Cultura. In: ASTRAIN, Ricardo Salas (Coord.). Pensamiento crítico latinoamericano: conceptos fundamentales. Santiago do Chile: Ed. UCSH, v. 1, 2005.

SANTOS, Boaventura de Souza. Pela mão de Alice: o social e o político na pós-modernidade. São Paulo: Cortez, 2000.

. Seis razões para pensar. Lua Nova: Revista de Cultura e Política, São Paulo, n. 54, p. 11-42, 2001. Disponível em: < http://www. scielo.br/scielo.php?pid $=$ S0102-64452001000300003\&script $=$ sci arttext > .Acesso em: 20/03/2011.

Por que é que Cuba se transformou num problema difícil para a esquerda? Oficina do CES, Centro de Estudos Sociais, Coimbra, n. 322, 2009. Disponível em: < http://www.boaventuradesousasantos. pt/media/Por\%20que\%20\%C3\%A9\%20que\%20Cuba_Oficina\%20322. pdf> . Acesso em: 29/03/2011.

STRECK, Danilo. Pedagogia do oprimido. In: STRECK, Danilo; REDIN, Euclides; ZITKOSKI, Jaime José (Org.). Dicionário Paulo Freire. São Paulo, 2008.

SOUZA, José Cavalcante de (Org.). Os pensadores pré-socráticos. São Paulo: Nova Cultural, 1996.

Eliana P. G. de Moura, doutora em Educação pela Pontifícia Universidade Católica do Rio Grande do Sul (PUC-RS), é docente/ pesquisadora do Programa de Pós-Graduação (Mestrado) em Inclusão Social e Acessibilidade da Universidade Feevale.

elianapgm@feevale.br 
Dinora Tereza Zucchetti, doutora em Educação pela Universidade Federal do Rio Grande do Sul (UFRGS), é docente/pesquisadora do Programa de Pós-Graduação (Mestrado) em Inclusão Social e Acessibilidade da Universidade Feevale.

dinora@feevale.br

Magali Mendes de Menezes, doutora em Filosofia pela Pontifícia Universidade Católica do Rio Grande do Sul (PUC-RS), é docente da Faculdade de Educação da Universidade Federal do Rio Grande do Sul (Faced/UFRGS).

magalimm@terra.com.br

Recebido em $1^{\circ}$ de junho de 2011.

Aprovado em 20 de outubro de 2011. 